\title{
Assessing the Restoration Success of River Widenings: A Landscape Approach
}

\author{
SIGRUN ROHDE* \\ FELIX KIENAST \\ MATTHIAS BÜRGI \\ Swiss Federal Research Institute WSL \\ $\mathrm{CH}-8903$, Birmensdorf, Switzerland
}

ABSTRACT / During the last 200 years, many rivers in industrialized countries have been modified by canalization. In the last two decades, the philosophy of river management has changed considerably, and restoration of ecological integrity has become an important management goal. One appealing restoration approach is to create "river widenings" that permit braiding within a limited area. This study presents a new and efficient framework for rapidly assessing such widening projects and offers a novel method to comparing restored sites with near-natural stretches (stencil technique). The proposed framework evaluates spatial patterns of riparian habitat types using landscape metrics as indicators. Three case studies from river restoration (river widening) in Switzerland are pre- sented for demonstration purposes. The method compares restored sites with prerestoration conditions and near-natural conditions, which are assumed to represent the worst and best case states of a river system. To take into account the limited spatial extent of the restored sites, the so-called "stencil technique" was developed, where the landscape metrics of the near-natural reference sites are calculated for both the entire study area and smaller sections (clips). The clips are created by using a stencil that has the exact shape and size of the restored area (random windowsampling technique). Subsequently, the calculated metrics for the restored sites are compared to the range of values calculated for the near-natural data subset. Our studies show that the proposed method is easy to apply and provides a valid way to assess the restoration success of river widenings. We found that river widenings offer real opportunities for establishing riparian habitats. However, they promote mainly pioneer successional stages and the habitat mosaic of the restored section is more complex than at the near-natural reference sites.
Riparian zones are widely acknowledged as being biodiversity hot spots (Malanson 1995; Naiman and others 1993). However, in Europe, only small areas have been left in a relatively undisturbed condition. Most rivers have been subjected to a variety of human impacts, primarily regulation. These engineering works have led to uniform landscapes characterized by canalized rivers lined with flood levees. As a result, the riparian zones have lost their natural dynamics and patterns, with a consequent decline in habitat and species diversity (Nilsson and Svedmark 2002; Pedroli and others 2002; Petts and Calow 1996). A new approach to river management in the last 20 years has meant that an increasing number of restoration projects have been initiated. One measure is to create river widenings that permit braiding within a limited area.

KEY WORDS: Stencil technique; Indicators; Assessment; Landscape metrics; GIS; Random window sampling; Riparian habitat; River restoration; Switzerland

Published online October 22, 2004

*Author to whom correspondence should be addressed; email: rohde@wsl.ch
These measures seek to mimic natural patterns and processes and, thus, return the fluvial ecosystem to a close approximation of its condition prior to canalization. Despite the increasing number of river restoration projects, postproject evaluation has generally been neglected (Kondolf and Micheli 1995). Presumably, the reasons for this are limited financial resources and the lack of evaluation schemes that are efficient and easy to apply. Where postproject evaluation has been undertaken, it has concentrated on in-stream characteristics like channel geomorphology and channel wildlife (Brunke 2002; Downs 2001; Gilvear and others 2002; Henry and others 2002; Thomson and others 2001) and largely disregarded the adjacent riparian landscape. Thus, the purpose of our study was to establish a framework for rapidly assessing restoration projects that aim to restore riparian landscapes, including (semi) terrestrial habitat types (riparian zone).

The specific aims of the study are as follows: (1) to develop a powerful and efficient method to assess the improvements achieved by the restoration measures in comparison with regulated and near-natural conditions; (2) to identify easily surveyed indicators that appropriately reflect landscape functions and pro- 


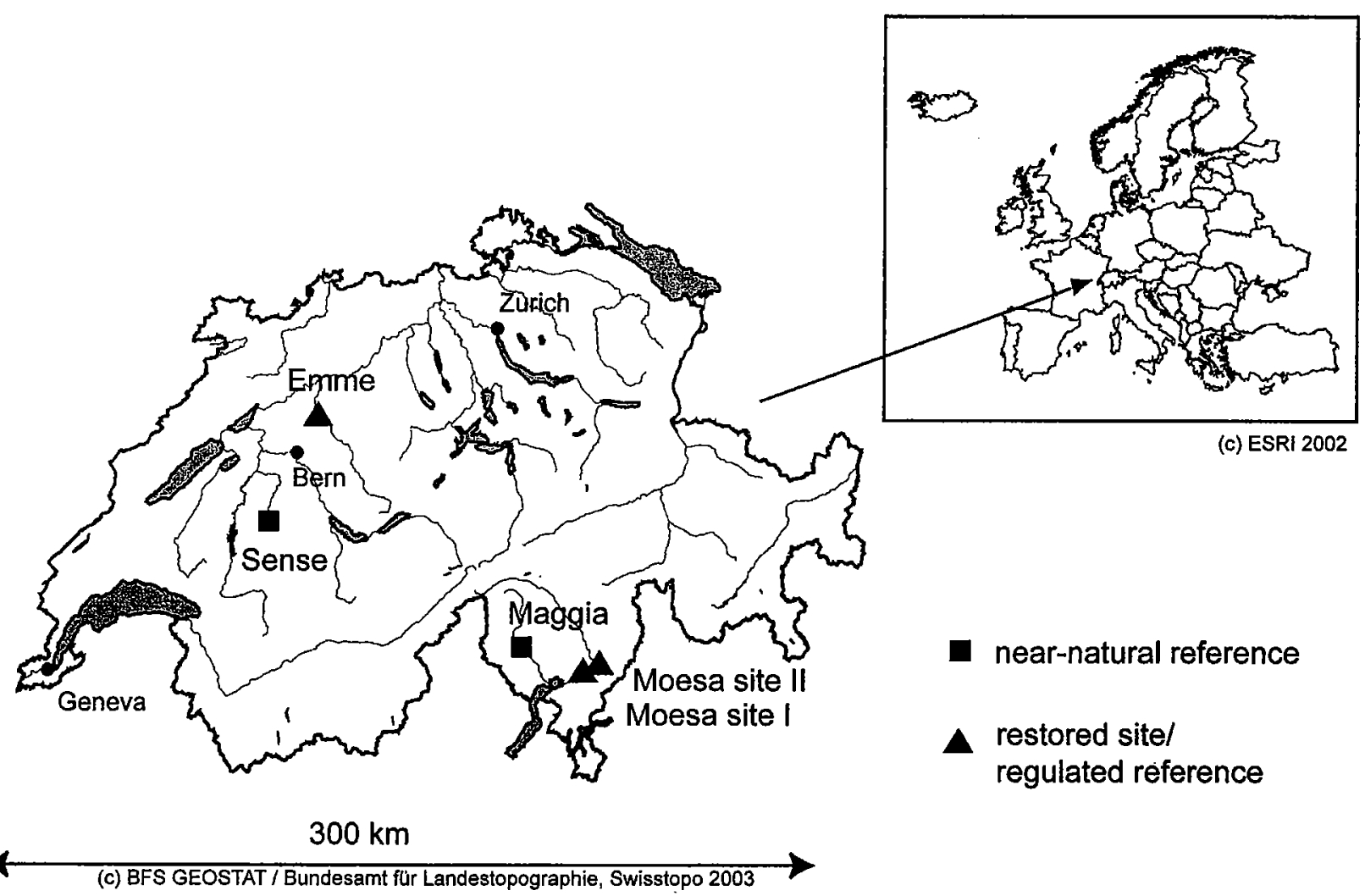

Figure 1. Case study sites.

cesses, and (3) to determine whether river widenings are suitable for re-establishing riparian zones.

Three case studies of river restoration projects are presented for demonstration purposes.

\section{Case Study Sites}

In the case studies, we analyzed three river restoration projects (river widenings) in Switzerland (see Figure 1). All river widenings are about 5 ha in size. The first site is located at the Emme River in the community of Aefligen in the northwestern part of Switzerland; the second and third sites are both located in the southern part of Switzerland along the Moesa River near the villages of Grono and Lostallo. Both rivers have been greatly affected by human activity, mainly through canalization. Restoration along the Emme River started around 1991. Embankments were removed on both sides and the channel was widened from $30 \mathrm{~m}$ to $85 \mathrm{~m}$ over a length of about $500 \mathrm{~m}$. After widening, groins were installed every $35-50 \mathrm{~m}$ to protect the banks. At Grono (Moesa site I), the restoration work started in winter/spring 1999. The forests on both sides were cleared over a length of up to $600 \mathrm{~m}$ and the river bed was widened by up to $50 \mathrm{~m}$. To allow for undisturbed, hydrogeomorphic processes, no bank protections were installed, except at the downstream end of the widening. The river widening at Lostallo (Moesa site II) was undertaken in 1997. As part of the restoration project, the right embankment was relocated to allow the channel to be widened from $20 \mathrm{~m}$ up to $85 \mathrm{~m}$. The relocated dam was protected by groins. Excavation material was used to build banks (1 m high) in the channel.

The Sense river near Plaffeien and the Maggia near Someo (see Figure 1) were selected for natural reference, as there has been little or no human impact on their hydrogeomorphic processes. Both sites belong to the most natural floodplains found in Switzerland (Gallandat and others 1993). The restored sites and corresponding near-natural references can be seen at a glance in Figure 2. Information on the abiotic conditions at each site is given in Table 1.

\section{Methods and Database}

\section{Selection of Case Study Sites}

As restoration is intended to return an ecosystem to a close approximation of its condition prior to disturbance, information about the pristine status is needed 


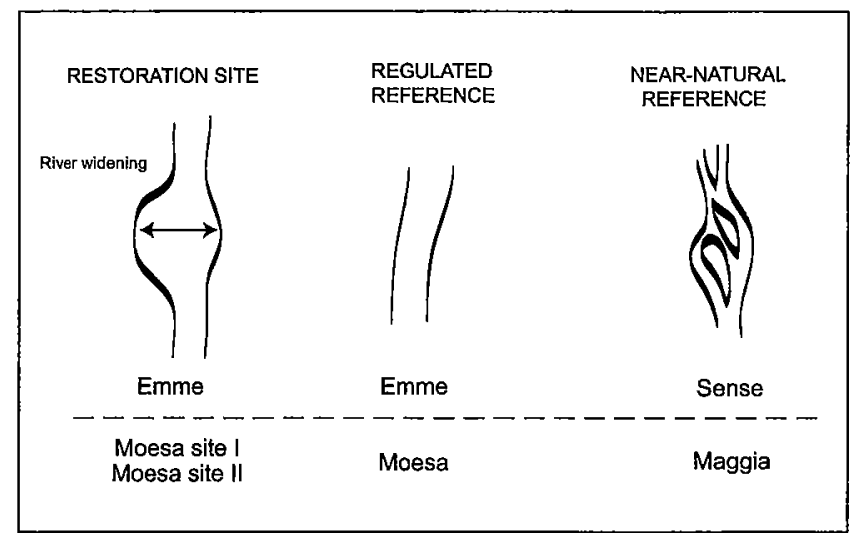

for comparison as part of the evaluation process. How can we obtain this information? Historical data are often rather poor. If historic sources are available, they need to be interpreted with a source-critical approach (Bürgi and Russel 2001). However, this is too timeconsuming to be implemented into a rapid assessment scheme. Instead, we can use data from present natural or near-natural sites as references for the evaluation of restoration measures (Milner 1996). To be suitable as a reference, the abiotic conditions of the near-natural reach must be similar to those found at the restoration site. Table 1 presents a set of criteria that are useful for selecting reference sites. They include biogeographical as well as geomorphological and hydrological properties. We also investigated the regulated status, which is the status before restoration took place. This allows us to evaluate the improvements achieved by the restoration process. Hence, two reference situations were chosen, as we presumed that the near-natural and the regulated reaches would define the boundaries for the "best" and "worst" conditions, respectively, and that the restored sites would be located somewhere between these extremes (Downs 2001).

\section{Habitat Maps}

Information on the riparian landscape (diversity and configuration of habitat types) was obtained by analyzing stereo pairs of photographs (1:5000 Color Infrared [CIR]) for the restored sites and for the nearnatural reaches. To correct for any distortion found in a normal aerial photograph, we converted all images to orthophotos, using Erdas Imagine 5.1 (Leica Geosystems). The prerestoration, regulated situation was reconstructed with maps and photographs provided by the local authorities. Information about vegetation height and vegetation cover was added to document the variety of structural features and different successional stages present within the floodplains. Table 2
Figure 2. Study design and study sites: comparison of the restored sites (river widening) with the situation prior to restoration (regulated reference) and with near-natural conditions (near-natural reference) to assess restoration success. gives detailed information about the habitat types that were distinguished. The interpretation was verified in field surveys to avoid misleading results due to misinterpretation, especially of vegetation height. Digital vector maps of habitat cover were produced in ArcView 3.3 GIS (Global information System) with a minimum patch size of $50 \mathrm{~m}^{2}$. The spatial resolution, scale, number of classes ,and accuracy of data processing markedly influence the subsequent metrics calculation (Blaschke and Petch 1999; Frohn 1998; Riitters and others 1995). Thus, a clear and standardized method for the mapping process must be applied to minimize biases arising from the mapping. For the calculation of the landscape metrics, the vector maps were transformed into raster maps (grid size $=1 \mathrm{~m}^{2}$ ). Depending on the resolution, patches can be split or merged by the algorithm when converting from vector format to raster format. Hence, it was necessary to carefully check the resulting raster maps for accuracy and artifacts. Errors resulting from the conversion process were reversed manually before the landscape metrics calculation.

\section{Landscape Metrics}

Landscape metrics were calculated to compare the landscape pattern of the restored sites with those of the regulated and the near-natural site. Landscape metrics quantify landscape composition and configuration (spatial arrangement). This allows us to assess whether (and how much) the landscape pattern had shifted toward near-natural conditions. The heterogeneity of landscape matrices and the structure of specific boundaries in landscapes determine the movement of organisms, materials, and energy (Pickett and Cadenasso 1995). Hence, landscape metrics can be interpreted as surrogates for the (inner) organization of a system, which reflects landscape functions and processes (Forman and Godron 1986; Miller and others 
Table 1. Characteristics of the restored ( $\mathrm{rs}$ ) and near-natural study sites (nr)

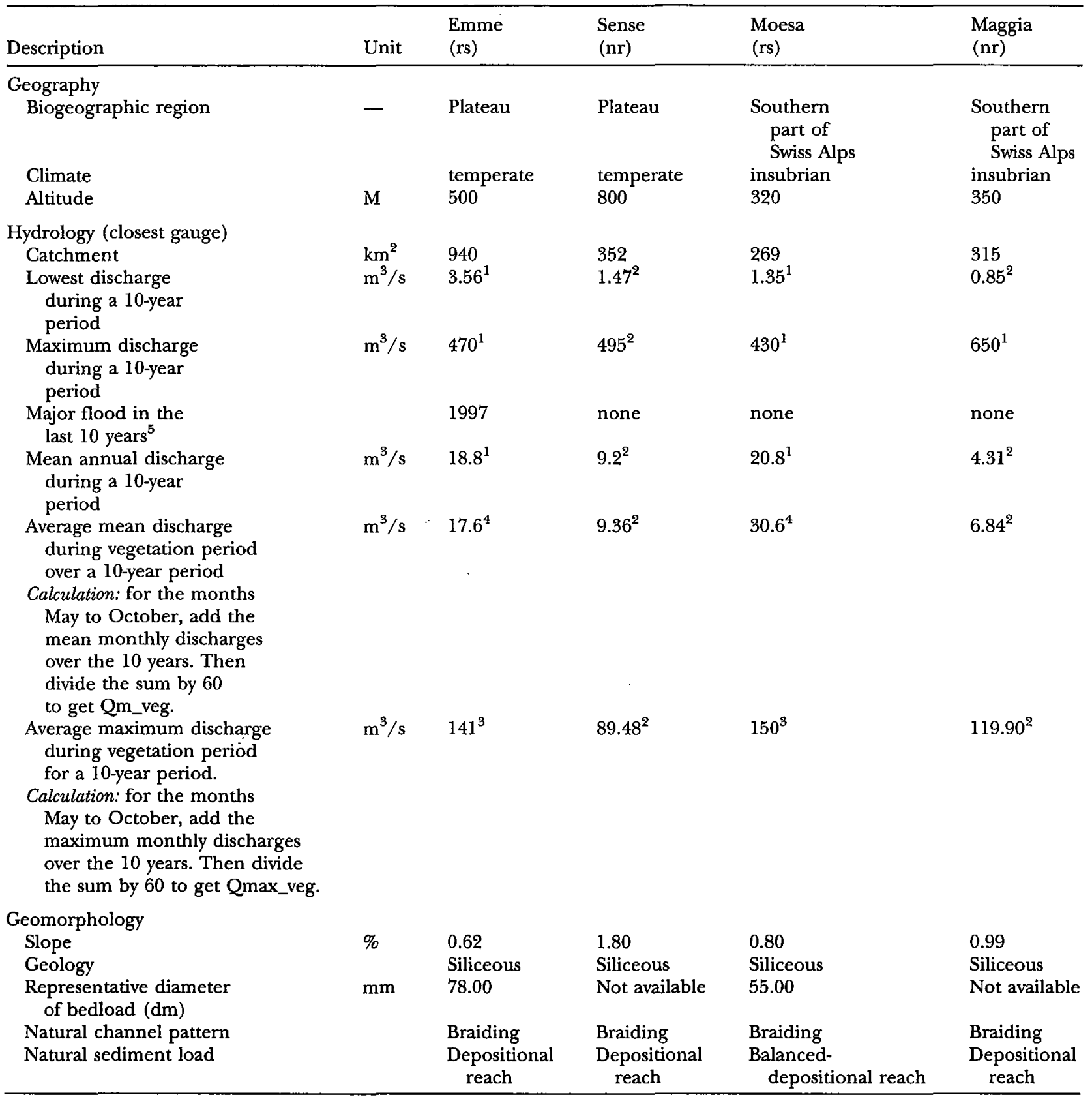

${ }^{1}$ Data from D. Streit (Federal Office for Water and Geology) (1991-2000).

${ }^{2}$ Data from the Riparian Zones Information Center, Yverdon (1986-1995).

${ }^{3}$ Own calculations based on data from D. Streit (Federal Office for Water and Geology) (1992-2001).

${ }^{4}$ Own calculations based on data from D. Streit (Federal Office for Water and Geology) (1991-2000).

${ }^{5}$ Major flood: registered discharge was as high as the annual peak discharge for a 10-year flood recurrence period with the probability 0.1 .

1997). Table 3 gives examples of the link between landscape configuration/composition and landscape processes and community ecology.

During the last 20 years, numerous metrics have been proposed, many of them strongly correlated
(Gustafson 1998; McGarigal and Marks 1995; Turner and others 2001). Thus, one needs to select a manageable set of independent metrics to describe landscape composition and landscape configuration (Herzog and others 2001; Li and Reynolds 1994; Riit- 
Table 2. Codes for 3-digit habitat type classification (X:Y:Z)

\begin{tabular}{ll}
\hline Habitat type (X) & \\
\hline 1 & Water \\
2 & Bare gravel bar \\
3 & Gravel bar with \\
pioneer vegetation \\
Riparian bushes \\
4 & and woodland \\
& Non-riparian bushes \\
5 & Forests \\
6 & Anthropogenic \\
7 & habitat types \\
& Reeds \\
8 & \\
Vegetation & $10-20 \%$ \\
cover (Y) & $20-40 \%$ \\
1 & $40-60 \%$ \\
2 & $60-80 \%$ \\
3 & $80-100 \%$ \\
4 & $5-10 \%$ \\
5 & \\
6 & \\
Vegetation & $0-1 \mathrm{~m}$ \\
height (Z) & $1-3 \mathrm{~m}$ \\
1 & $3-5 \mathrm{~m}$ \\
2 & $>5 \mathrm{~m}$ \\
4 & \\
4 & \\
\hline
\end{tabular}

Note: Habitat types and additional information on vegetation cover and vegetation height were obtained from CIR-orthophotos.

ters and others 1995). Landscape composition is quantified by the number and proportion of land-cover types, whereas landscape configuration can be summarized as the spatial arrangement of patches, the number and size of patches, the occurrence of edges, and the patch compaction (Herzog and others 2001; Lausch and Herzog 2002; $\mathrm{Li}$ and Reynolds 1994; Riitters and others 1995). These studies show that a small set of metrics suffices to capture the principal properties of the landscape under consideration. This small set of metrics, however, could differ depending on the restoration types (e.g., woodland restoration, river restoration, and mire restoration). Our selection of metrics is based on the studies of Herzog and others (2001), Lausch and Herzog (2002), Li and Reynolds (1994), Riitters and others (1995), and our own theoretical considerations, with the focus on key features of riparian landscape pattern and their restoration (Table 3). We reduced the number of metrics to the most significant ones and a correlation analysis was performed to ensure that the metrics were relatively independent (Pearson correlation coefficient $\leq 0.46$ ).

The raster version of PatchAnalyst (Elkie and others 1999) was used for the landscape metric calculations. For each site, the selected landscape metrics were computed at the landscape level. The area covered either by water or bare gravel depends on the water level. To avoid artifacts caused solely by varying water levels, we treated water and bare gravel bars as a single, combined habitat type named "amphibious."

Because we suspected that there might be differences between the calculation at the landscape level and at the level of habitat types (class level), we calculated the metrics for gravel bars with pioneer vegetation, which are of special interest from a conservation point of view.

We were also interested in finding out how far the present river widening deviates from the prerestoration status before and from a near-natural status. For comparison, we used the City Block Distance, also called the "Manhattan" metric. This metric compares two cases, $i$ and $j$, and is the sum of the distances on each variable, defined as follows (see also http://www.clustan.com/general_distances.html):

$$
d_{i j}=\frac{\sum_{k} w_{i j k}\left|x_{i k}-x_{j k}\right|}{\sum_{k} w_{i j k}}
$$

where $x_{i k}$ is the value of variable $k$ in case $i$ and $w_{i j k}$ is a weight of 1 or 0 depending on whether or not the comparison is valid for the $k$ th variable (if differential variable weights are specified, it is the weight of the $k$ th variable). The Manhattan metric aggregates the individual metrics into a single figure, which allows the restoration measure to be rated on a scale of naturalness running from radically altered (canalized) to nearnatural.

\section{Data Subset Clips}

General considerations. An evaluation of restoration projects should be conducted in two steps. First, the restored area should be compared with the regulated reference to detect any changes in the landscape patterns due to the restoration process. Second, and this is important, the restored area and a near-natural reference should be compared to see if the restored area matches the patterns inherent to a natural system. If significant differences are found, the different sizes (spatial extents) of the areas under investigation should be considered, because the spatial extent of the map (window size) has been shown to considerably influence the values of landscape metrics (Hunsaker and others 1994; $\mathrm{Qi}$ and Wu 1996; Turner and others 1989), especially those relating to patch complexity (Saura and Martinez-Millan 2001). Therefore, caution is necessary when comparing areas of different size. The influence of area size can be reduced either by calculating the metrics on the basis of a standard unit area (Freeman and others 2003) (but this cannot be 
Table 3. Landscape metrics and definitions related to selected landscape functions and processes

\begin{tabular}{|c|c|c|}
\hline Metric & Definition $^{1}$ & $\begin{array}{l}\text { Examples of postulated, associated } \\
\text { landscape functions/processes }\end{array}$ \\
\hline \multicolumn{3}{|c|}{ Landscape composition } \\
\hline PR & $\begin{array}{l}\text { Patch Richness: measures } \\
\text { the number of patch } \\
\text { types present }\end{array}$ & $\begin{array}{l}\text { Habitat diversity is a } \\
\text { prerequisite for } \\
\text { species diversity. }\end{array}$ \\
\hline \%Area & $\begin{array}{l}\text { Percentage of landscape } \\
\text { occupied by each patch type }\end{array}$ & $\begin{array}{l}\text { Habitat availability has } \\
\text { a strong influence } \\
\text { on species populations }\end{array}$ \\
\hline \multicolumn{3}{|c|}{ Landscape configuration } \\
\hline MSI & $\begin{array}{l}\text { Mean Shape Index: measures } \\
\text { shape complexity of a patch } \\
\text { compared to a standard shape } \\
\text { (square for raster format) }\end{array}$ & $\begin{array}{l}\text { The number of organisms } \\
\text { can be a function of } \\
\text { patch shape (Hamazaki 1996). }\end{array}$ \\
\hline medPS & Median Patch Size (ha) & $\begin{array}{l}\text { Patch size is a key feature } \\
\text { for suitable habitats. }\end{array}$ \\
\hline MNN & $\begin{array}{l}\text { Mean Nearest Neighbor: measures } \\
\text { the distance from a patch to } \\
\text { the nearest neighboring patch } \\
\text { of the same type, based on } \\
\text { edge-to-edge distance }(\mathrm{m})\end{array}$ & $\begin{array}{l}\text { Dispersal and thus species } \\
\text { colonization and the } \\
\text { conservation of } \\
\text { metapopulations are } \\
\text { determined by the } \\
\text { distance between } \\
\text { suitable habitats. }\end{array}$ \\
\hline MPI & $\begin{array}{l}\text { Mean Proximity Index: measures } \\
\text { the degree of isolation and } \\
\text { fragmentation. MPI uses the } \\
\text { nearest neighbor statistics and } \\
\text { considers additionally the size } \\
\text { of neighboring patches. }\end{array}$ & \\
\hline IJI & $\begin{array}{l}\text { Interspersion and Juxtaposition Index: } \\
\text { measure of patch adjacency. } \\
\text { IJI }=100 \text { if all patch types are } \\
\text { equally adjacent to all other patch types }\end{array}$ & $\begin{array}{l}\text { The suitability of a site as } \\
\text { habitat for species with } \\
\text { multiple habitat requirements } \\
\text { depends on interspersion } \\
\text { and juxtaposition of } \\
\text { different habitat types. }\end{array}$ \\
\hline ED & $\begin{array}{l}\text { Edge Density: standardizes total } \\
\text { edge length to a per unit } \\
\text { area basis }(\mathrm{m} / \mathrm{ha})\end{array}$ & $\begin{array}{l}\text { - Water cycle regulation } \\
\text { is a function of the } \\
\text { shoreline (= ecotone length). } \\
\text { - The area of water-substrate } \\
\text { interface (i.e., wetland-upland } \\
\text { length of contact) is } \\
\text { positively correlated } \\
\text { with the efficiency of } \\
\text { nitrogen retention } \\
\text { (Pinay and others 2002). } \\
\text { - Some species are more } \\
\text { related to the extent/length } \\
\text { of wetland edge than to the } \\
\text { total amount of wetland } \\
\text { (Browder and others 1989). } \\
\text { - Diversity of juvenile fish, } \\
\text { benthic invertebrates, and } \\
\text { riparian ground beetles is } \\
\text { positively related to shoreline } \\
\text { length (Wintersberger 1996; } \\
\text { Elkie and others 1999; } \\
\text { Hering and Plachter 1997) }\end{array}$ \\
\hline
\end{tabular}

\footnotetext{
${ }^{1}$ For details, see McGarigal and Marks (1995).
} 


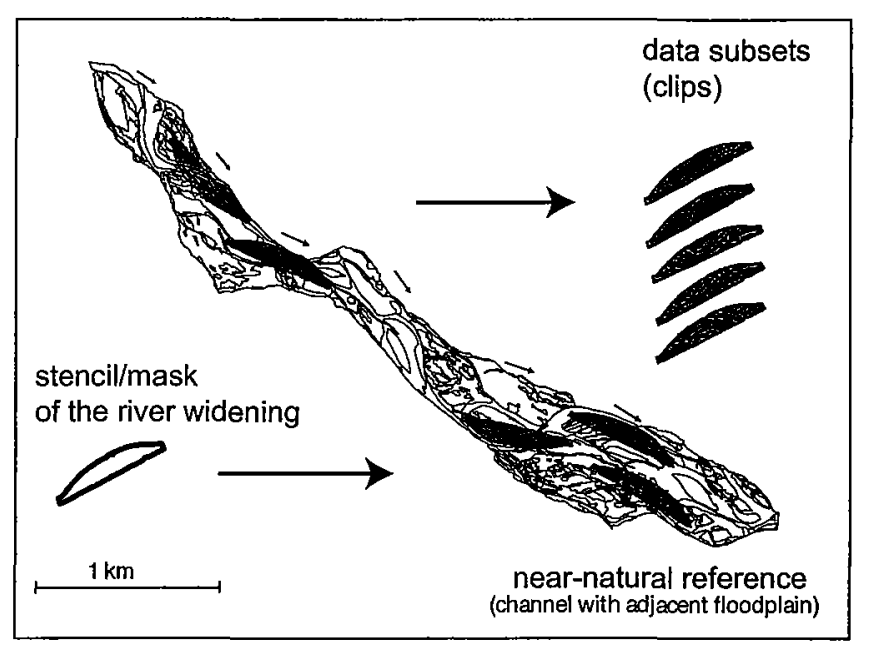

done for every metric) or by comparing the restored sites with a subset of near-natural areas of the same size and shape as the restored sites. The latter approach is the one we used in this study. This approach is similar to the random window-sampling technique used in studies of habitat selection in wildlife ecology (Mladenoff and others 1995; Potvin and others 2001; Ripple and others 1991). Instead, however, of using a square window, we created a mask of the same shape and size as the restored area to produce a data subset of comparable size from the near-natural reference sites. For the near-natural data subsets, the mean/median and range were calculated for each selected metric and compared with the values obtained from the restored/ regulated sites. The statistical analysis was conducted with SPSS 11.0 for Windows.

Subset generation. A size- and shape-matched stencil ("window") of the restored area was produced by means of the GIS. This stencil was used to cut out the subset of the habitat map of the natural reference using the clip function in ArcMap 8.1 (see Figure 3). The stencil was positioned on the habitat maps with stencil centroids at randomly selected grid points on a $50-\mathrm{m}^{2}$ grid. Only those grid points that allowed a complete overlap between the stencil and the natural reference habitat map were used. The orientation of the stencil followed the mean stream direction. If a landscape patch was truncated by the edge of the stencil, the portion of the patch within the stencil was included to ensure that the sample unit was constant. Sampling with overlapping was allowed, facilitating the representation of all the landscape patterns that occur under near-natural conditions (Potvin and others 2001).

The number of clips needed within a subset depends on the variability of the metric values within the
Figure 3. Stencil technique: generation of data subsets (clips) of the near-natural reference, using a stencil with the same size and shape as the river widening. Stencil orientation followed the main flow direction $(\downarrow)$. subset. The clipping process proceeded until the additional variability obtained approached zero $\left(\Delta V=V_{n+1}-V \approx 0\right)$. As the data were not normally distributed, the standard deviation and variance could not be used to describe the variability. Instead, we calculated the variability as half of the interquartile range (IQR) as a percentage of the median $(M)$ :

$$
V=\frac{0.5^{*} \mathrm{IQR}}{M}
$$

(Lamprecht 1992). Based on $\Delta V$, the variability analysis showed that a sample size of 12 random windows ensured that the variability was stable [ (except for MPI at the site of Lostallo (Moesa)]. Consequently, we used a set of 15 clips for the following investigations.

\section{Results}

\section{Comparing the Entire Study Areas}

Regarding the landscape composition, we found a good match between the habitat types in the restoration sites and in their corresponding near-natural reference sites (see Table 4). Solely, site I at the Moesa had only four habitat types in common with the nearnatural reference. The restoration measures at the Emme River and Moesa site II have led to considerable improvements and more natural conditions with respect to the patch richness and number of riparian habitats. Looking at the habitat types that consistently appear at the restoration sites, we can see that river widenings mainly promote young seral stages such as gravel bars with pioneer vegetation and riparian shrub (see Table 4). Late seral stages (riparian woodlands) are missing unless they are remnants that were formerly disconnected from the stream. The patch rich- 
Table 4. Landscape composition (diversity) of the restoration sites ( $\mathrm{rs}$ ), corresponding regulated ( $\mathrm{rr}$ ), and nearnatural $(\mathrm{nr})$ references (-: habitat type not present)

\begin{tabular}{|c|c|c|c|c|c|c|c|c|c|c|}
\hline Habitat type & $\begin{array}{l}\text { Veg. } \\
\text { cover } \\
(\%)\end{array}$ & $\begin{array}{l}\text { Veg. } \\
\text { height } \\
\text { (m) }\end{array}$ & $\begin{array}{l}\text { Emme } \\
\text { (rs) } \\
\text { \%Area }\end{array}$ & $\begin{array}{l}\text { Emme } \\
(\mathrm{rr}) \\
\text { \%Area }\end{array}$ & $\begin{array}{l}\text { Sense } \\
\text { (nr) } \\
\% \text { Area }\end{array}$ & $\begin{array}{l}\text { Moesa } \\
\text { site I } \\
\text { (rs) } \\
\% \text { Area }\end{array}$ & $\begin{array}{l}\text { Moesa } \\
\text { site I } \\
\text { (rr) } \\
\% \text { Area }\end{array}$ & $\begin{array}{l}\text { Moesa } \\
\text { site II } \\
\text { (rs) } \\
\text { \%Area }\end{array}$ & $\begin{array}{l}\text { Moesa } \\
\text { site II } \\
\text { (rr) } \\
\text { \%Area }\end{array}$ & $\begin{array}{l}\text { Maggia } \\
\text { (nr) } \\
\% \text { Area }\end{array}$ \\
\hline Water & & & 37.09 & 27.39 & 19.24 & 84.91 & 35.40 & 46.66 & 32.64 & 10.43 \\
\hline Bare gravel bars & & & 13.51 & - & 23.13 & 14.15 & - & 19.01 & - & 31.89 \\
\hline \multirow{6}{*}{$\begin{array}{l}\text { Gravel bars with } \\
\text { pioneer } \\
\text { vegetation }\end{array}$} & $5-10$ & & 1.58 & - & 4.19 & - & - & 3.93 & - & 1.56 \\
\hline & $10-20$ & $0-1$ & 0.35 & - & 1.69 & 0.74 & - & - & - & 1.31 \\
\hline & $20-40$ & $0-1$ & 2.72 & - & 4.05 & 0.2 & - & 0.24 & - & 4.69 \\
\hline & $40-60$ & $0-1$ & 0.22 & - & 0.87 & - & - & - & - & 0.51 \\
\hline & $60-80$ & $0-1$ & 2.15 & - & 0.31 & - & - & 0.35 & - & 0.73 \\
\hline & $80-100$ & $0-1$ & 1.98 & 一 & 0.06 & - & - & 1.12 & 一 & 0.32 \\
\hline \multirow{4}{*}{$\begin{array}{l}\text { Riparian } \\
\text { shrubs }\end{array}$} & $20-40$ & $1-3$ & 0.68 & - & 5.74 & - & 一 & 5.51 & - & 12.62 \\
\hline & $40-60$ & $1-3$ & 0.11 & 一 & 3.55 & - & - & 3.65 & - & 3.91 \\
\hline & $60-80$ & $1-3$ & 0.19 & - & 3.7 & - & - & 1.17 & - & 2.15 \\
\hline & $80-100$ & $1-3$ & 7.67 & 22.83 & 2.22 & - & - & 4.95 & - & 1.98 \\
\hline \multirow{7}{*}{$\begin{array}{l}\text { Riparian } \\
\text { woodland }\end{array}$} & $20-40$ & $3-5$ & - & - & - & - & - & - & - & 2.47 \\
\hline & $40-60$ & $3-5$ & - & - & 0.18 & - & - & - & - & 1.79 \\
\hline & $60-80$ & $3-5$ & - & - & 0.44 & - & - & - & - & 0.87 \\
\hline & $80-100$ & $3-5$ & 10.68 & - & 8.22 & - & - & 1.6 & - & 8.23 \\
\hline & $20-40$ & $>5$ & - & 一 & - & - & - & - & - & 0.02 \\
\hline & $40-60$ & $>5$ & $\ldots$ & - & 0.08 & - & - & - & - & - \\
\hline & $60-80$ & $>5$ & 18.51 & - & 20.16 & - & - & - & - & 14.27 \\
\hline Non-riparian shrub & & & 1.34 & - & - & - & - & 6.89 & 9.63 & - \\
\hline Non-riparian woodland & & & 0.64 & 42.38 & - & - & 64.40 & 2.47 & $\mathbf{5 7 . 7 3}$ & - \\
\hline Anthropogenic & & & 0.58 & 7.4 & 2.15 & 一 & - & 2.46 & - & 0.25 \\
\hline Patch richness & & & 17 & 4 & 18 & 4 & 2 & 14 & 3 & 19 \\
\hline $\begin{array}{l}\text { Number of } \\
\text { riparian habitats }\end{array}$ & & & 14 & 2 & 17 & 4 & 1 & 11 & 1 & 18 \\
\hline Total area (ha) & & & 4.86 & 4.86 & 55.48 & 5.18 & 5.18 & 4.7 & 4.7 & 150.59 \\
\hline
\end{tabular}

ness metric is a diversity measure based on the presence of a habitat type regardless of the proportion of landscape occupied by the individual habitat type. As there are many species that have strict minimum habitat area requirements, it is also important to consider the area occupied by the individual habitat types. Table 4 shows that $\sim 40 \%$ of the area in near-natural stretches is covered by amphibious habitats. In contrast, the restoration sites have a much higher percentage of either water or bare gravel bars (Emme $50 \%$, Moesa site I 99\%, Moesa site II 65\%). Thus, the river widenings provide a significantly lower percentage of habitats for species that avoid amphibious ground than do the near-natural sites. At the restoration site of Aefligen (Emme), no differences in habitat occupation could be found for gravel bars with pioneer vegetation and riparian woodlands. In contrast, both restoration sites at the Moesa differ (in some respects significantly) from their near-natural reference site at the Maggia River (see Table 4). Thus, habitat compo- sition at the restoration site of the Emme is more natural than at the sites along the Moesa.

In contrast to the landscape composition, we found distinct differences in landscape configuration between the restored sites and the near-natural references. The pattern of the widenings consists of smaller and more elongated patches, resulting in markedly higher edge densities (see Table 5). For the restored sites at the Emme and Moesa site II, for example, the median patch size is less than half the size of the median patch size in the corresponding near-natural reference site. Our data show that the Mean Shape Index (MSI) generally increases with decreasing naturalness, which means that the more natural a site is, the more compact and less elongated the patches are (see Table 5). Hence, a decrease in MSI indicates more interior habitats and fewer edge effects. Generally speaking, the restoration measures lead to a more natural habitat configuration, but the resulting pattern is patchier than the pattern of the near-natural 
Table 5. Landscape configuration of the restoration sites ( $r s$ ), corresponding regulated ( $r r)$ and near-natural (nr) references. Note that these are values obtained from the entire study areas, which have not been corrected to take into account the different sizes of the sites. This correction can be performed with the proposed stencil technique (see Figure 5)

\begin{tabular}{lrrrrrrrrr}
\hline Metric & $\begin{array}{l}\text { Emme } \\
(\mathrm{rs})\end{array}$ & $\begin{array}{l}\text { Emme } \\
(\mathrm{rr})\end{array}$ & $\begin{array}{l}\text { Sense } \\
(\mathrm{nr})\end{array}$ & $\begin{array}{l}\text { Moesa site } \\
\text { I (rs) }\end{array}$ & $\begin{array}{l}\text { Moesa site I } \\
(\mathrm{rr})\end{array}$ & $\begin{array}{l}\text { Moesa site II } \\
(\mathrm{rs})\end{array}$ & $\begin{array}{l}\text { Moesa site II } \\
(\mathrm{rr})\end{array}$ & $\begin{array}{l}\text { Maggia } \\
(\mathrm{nr})\end{array}$ \\
\hline $\begin{array}{l}\text { Mean Shape } \\
\quad \text { Index }\end{array}$ & 2.41 & 4.73 & 2.07 & 2.50 & 2.68 & 2.41 & 3.94 & 2.33 \\
$\begin{array}{l}\text { Median patch } \\
\text { size }\end{array}$ & 0.02 & 0.63 & 0.05 & 0.06 & 1.84 & 0.04 & 1.53 & 0.09 \\
$\begin{array}{l}\text { Mean nearest } \\
\text { neighbor }\end{array}$ & 37.20 & 41.3 & 59.60 & 39.80 & 8.3 & 40.10 & - & 78.20 \\
$\begin{array}{l}\text { Mean proximity } \\
\text { index }\end{array}$ & 328.30 & 3.75 & 372.99 & 396.06 & 6089.37 & 176.79 & - & 1334.58 \\
$\begin{array}{l}\text { Interspersion \& } \\
\text { juxtaposition index }\end{array}$ & 68.57 & 61.31 & 66.02 & 29.35 & 0.00 & 68.90 & 63.08 & 71.37 \\
$\begin{array}{l}\text { Edge density } \\
\text { Total area (ha) }\end{array}$ & 1459.84 & 1081.30 & 1221.28 & 812.82 & 623.36 & 1470.91 & 699.47 & 759.16 \\
\hline & 4.86 & 4.86 & 55.48 & 5.18 & 5.18 & 4.7 & 4.7 & 150.59 \\
\hline
\end{tabular}

reaches. As can be seen from Table 6 , calculations at the level of habitat types (class level) revealed the same results as those for calculations at the landscape level, namely smaller median patch size, higher edge density and mean shape index, and fewer interspersed seral stages.

Landscape composition and configuration can be simultaneously assessed by means of the "Manhattan" metric $\left(d_{i j}\right)$, which is defined as the sum of the differences in the individual metrics. The calculated $d_{i j}$ values for the three widening projects are visualized in Figure 4. Overall, the restoration projects along the Emme River and at Moesa site II were rated as having closer to near-natural conditions than Moesa site I, where the restoration measures have led to only comparatively minor improvements.

\section{Comparing Data Subsets (Clips)}

When we looked at the natural reference as a whole, we found noticeable differences in the landscape configuration between the restored and near-natural reaches. We asked ourselves whether the differences would be as significant if we use the data subsets (clips) for comparison instead. The box plots of Figure 5 show the range of the metric values for each data subset and the value calculated for the restoration sites. For Emme and Moesa site II, we can see that the calculated metrics lie within the range of the corresponding data subset in most instances. This is especially true for Moesa site II, which matches all metrics except for edge density. The latter was still greater at this site than in the near-natural data subset. For Moesa site I, we find the same overall pattern as earlier in the comparison with the near-natural reference site as a whole.
Only three out of seven metrics are within the nearnatural range, reflecting the major differences between the restoration site and the near-natural stretch.

Looking at the individual metrics in more detail, we find that the Mean Nearest Neighbor Index (MNN) and the Mean Proximity Index are within the nearnatural range for all three restoration sites. For MNN, the values even lie within the interquartile range. In contrast, the restored sites differ markedly from the near-natural sites if we compare the values of these metrics with the reference as a whole. This applies particularly to Moesa site I. In general, it seems that the differences between the restored sites and the nearnatural stretches are less profound when the data subsets are compared rather than the natural reference as a whole.

\section{Discussion}

The methodological framework presented here is an attempt to provide a method for rapidly assessing restoration measures based on readily available habitat data. The method is based on calculations of landscape metrics calculation, stencil subset sampling, and comparisons of the restored sites with regulated/near-natural references. The results are so far promising, but the following aspects should be considered before drawing final conclusions.

\section{A Method Based on Mapping Habitat Types}

In our assessment, we used habitat-type mapping, which relies on the widely acknowledged relationship between site characteristics and species abundance (Amoros 2001). It could be argued that measuring 
Table 6. Configuration metrics calculated for gravel bars with pioneer vegetation at the restored site ( $r s$ ) and at the near-natural reference $(\mathrm{nr})$. There are no results for the regulated references as there were no gravel bars prior to restoration. (-:habitat type not present, 0.00 : only one patch present)

\begin{tabular}{|c|c|c|c|c|c|c|}
\hline $\begin{array}{l}\text { Landscape } \\
\text { metric }\end{array}$ & $\begin{array}{l}\text { Vegetation } \\
\text { cover }(\%)\end{array}$ & $\begin{array}{l}\text { Emme } \\
\text { (rs) }\end{array}$ & $\begin{array}{l}\text { Sense } \\
(\mathrm{nr})\end{array}$ & $\begin{array}{l}\text { Moesa I } \\
(\mathrm{rs})\end{array}$ & $\begin{array}{l}\text { Moesa II } \\
\text { (rs) }\end{array}$ & $\begin{array}{l}\text { Maggia } \\
(\mathrm{nr})\end{array}$ \\
\hline \multirow[t]{6}{*}{ Mean shape index } & $5-10$ & 2.65 & 2.06 & - & 2.28 & 2.46 \\
\hline & $10-20$ & 2.26 & 1.82 & 2.13 & - & 2.66 \\
\hline & $20-40$ & 2.12 & 2.13 & 1.47 & 2.17 & 2.64 \\
\hline & $40-60$ & 2.89 & 1.70 & - & - & 1.85 \\
\hline & $60-80$ & 1.84 & 1.66 & 一 & 2.57 & 2.54 \\
\hline & $80-100$ & 3.18 & 1.79 & - & 3.16 & 2.25 \\
\hline \multirow[t]{6}{*}{ Median patch size } & $5-10$ & 0.012 & 0.041 & - & 0.061 & 0.088 \\
\hline & $10-20$ & 0.0086 & 0.039 & 0.019 & - & 0.079 \\
\hline & $20-40$ & 0.066 & 0.078 & 0.01 & 0.011 & 0.13 \\
\hline & $40-60$ & 0.011 & 0.074 & - & - & 0.061 \\
\hline & $60-80$ & 0.044 & 0.051 & - & 0.017 & 0.071 \\
\hline & $80-100$ & 0.025 & 0.017 & - & 0.053 & 0.12 \\
\hline \multirow[t]{6}{*}{ Mean nearest neighbor } & $5-10$ & 25.46 & 74.15 & - & 66.49 & 97.09 \\
\hline & $10-20$ & 137.77 & 97.12 & 218.52 & - & 130.76 \\
\hline & $20-40$ & 101.98 & 89.41 & 0.00 & 0.00 & 44.49 \\
\hline & $40-60$ & 0.00 & 353.95 & - & - & 180.6 \\
\hline & $60-80$ & 75.26 & 127.08 & - & 0.00 & 418.87 \\
\hline & $80-100$ & 18.51 & 2259.88 & 一 & 0.00 & 110.27 \\
\hline \multirow[t]{6}{*}{ Mean Proximity Index } & $5-10$ & 0.61 & 9.59 & - & 0.36 & 6.95 \\
\hline & $10-20$ & 0.00 & 0.37 & 0.00 & - & 56.95 \\
\hline & $20-40$ & 0.06 & 4.04 & 0.00 & 0.00 & 20.88 \\
\hline & $40-60$ & 0.00 & 7.50 & 一 & 一 & 0.13 \\
\hline & $60-80$ & 0.10 & 0.50 & - & 0.00 & 1.42 \\
\hline & $80-100$ & 236.46 & 0.00 & - & 0.00 & 0.27 \\
\hline \multirow[t]{6}{*}{ Interspersion \& Juxtaposition Index } & $5-10$ & 64.74 & 72.14 & - & 73.06 & 83.65 \\
\hline & $10-20$ & 47.73 & 65.34 & 62.44 & - & 72.34 \\
\hline & $20-40$ & 33.79 & 77.49 & 61.82 & 29.15 & 78.37 \\
\hline & $40-60$ & 36.90 & 55.15 & - & - & 70.86 \\
\hline & $60-80$ & 56.92 & 50.60 & - & 27.02 & 70.71 \\
\hline & $80-100$ & 60.58 & 23.73 & - & 54.51 & 78.01 \\
\hline \multirow[t]{6}{*}{ Edge density } & $5-10$ & 143.72 & 92.55 & - & 144.37 & 44.11 \\
\hline & $10-20$ & 34.18 & 46.40 & 47.85 & - & 34.23 \\
\hline & $20-40$ & 87.30 & 87.50 & 11.58 & 19.59 & 69.29 \\
\hline & $40-60$ & 24.71 & 22.28 & - & - & 13.47 \\
\hline & $60-80$ & 81.13 & 9.66 & - & 28.11 & 18.51 \\
\hline & $80-100$ & 130.95 & 3.39 & - & 61.75 & 8.94 \\
\hline
\end{tabular}

species abundance would yield more accurate results. Although this might be the case, the following points should also be considered:

- First, the composition and configuration of habitat types reflect the potential for a typical biocoenosis to establish at a specific site. With our method, we are able to assess this potential (i.e., whether or not the observed patterns are similar to those in near-natural conditions). This is of primary interest in the evaluation of restoration projects, as restoration measures can mainly influence habitat conditions rather than species migration and colonization. The latter depends on time for colonization and on distance from seedling pools, as well as on habitat availability. Colonization by a given species can, therefore, be decelerated in time despite the existence of favorable habitat conditions.

- Second, there is often large variability in the abundance of individual species from year to year due to factors that lie outside the usual scale and control of a river restoration project. Therefore, it is unlikely that the assessment of individual species can provide much information about the likely sustainability of the scheme, which is a vital consideration for restoration designers (Downs 2001). The alternative is to exploit the proven link between species and their physical habitats and to assess the restoration project against its provision of a suitable habitat template (Downs 2001). Additionally, habitat maps are readily generated and cost-efficient, which is an important aspect considering the limited budget of many restoration projects. 


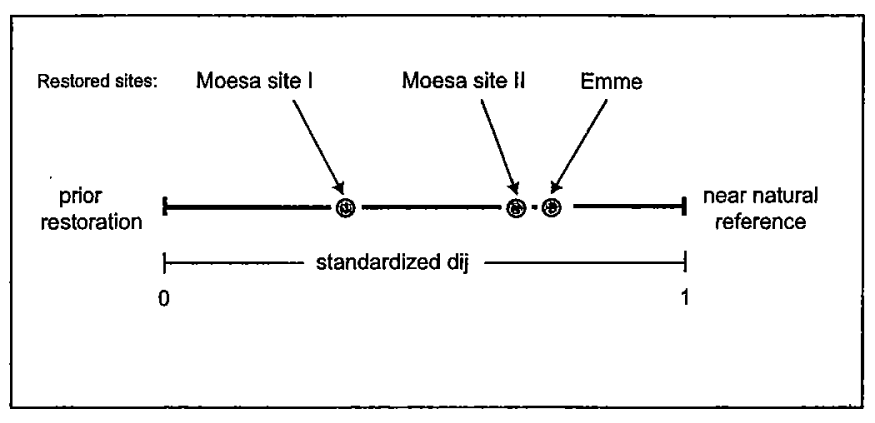

Figure 4. Rating of the restoration projects by means of the Manhattan metric $d_{i j}$ (city block distance) (standardized values: lowest $d_{i j}$ value $=0$, highest $d_{i j}$ value $=1$ ) .
When mapping habitat types, it is important to also map such structural and successional features as vegetation height and vegetation cover because floodplains are characterized by the presence of a wide range of successional stages due to fluvial dynamics in natural river ecosystems. Each successional stage is characterized by its own horizontal and vertical structures of plant cover, which provide different animal habitats. This structural and functional diversity determines the richness of species diversity within riparian communities. Mapping merely based on broad classes (e.g., forest, nonforest) and solely floristic characteristics does not account for this diversity. Therefore, vegetation cover and height need to be included in the mapping process. Vegetation cover can easily be mapped using air photographs (orthophotos). However, vegetation height might need field verification, depending on the area's topography.

Many indicators used for river (restoration) assessment focus on in-stream components (Gergel and others 2002; Innis and others 2000). Benthos, temperature, water chemistry, velocity, and so forth are important characteristics to be considered. However, an in-stream environment covers only $10-20 \%$ of the near-natural references studied. Thus, in-stream indicators are unable to assess a large portion of the floodplain. The (semi) terrestrial zone of a floodplain is generally characterized by a high habitat diversity and, consequently, high species richness, which should be considered when assessing restoration efforts. Additionally, processes in the riparian zone influence instream processes (Jones and others 1999; Weller and others 1998) (and vice versa). Therefore, information on (semi) terrestrial habitat types should be included to complement existing assessment schemes.

\section{A Formalized Assessment Based on Landscape Metrics}

Our primary purpose was to generate a rapid assessment method that compares habitat properties after restoration with both the state prior to restoration and the near-natural state. To do this we calculated the landscape metrics, which is readily done once habitat maps have been acquired.

When calculating landscape metrics, it is assumed that landscape patterns can be linked to landscape functions and processes (Forman and Godron 1986; Honnay and others 2003; Lausch and Thulke 2001). For an evaluation process, the individual metrics must be independent of each other to avoid weighting single aspects. Thus, the Pearsson correlation coefficient should ideally be less than 0.5 . However, the selection of the metrics should depend not only on the correlation coefficients but also on the questions to be answered, as it is clear that each index adds additional information about the pattern of a specific site.

The potential and limitations of the use of landscape metrics have been discussed by several authors (see Gustafson 1998; McGarigal and Marks 1995; Turner and others 2001), so only a brief comment will be made here. A major limitation is the open question of which change in metric value is ecologically signifcant (Turner and others 2001). Despite this limitation, we think that every change in value toward near-natural values is a step in the right direction and that the smaller the difference between the metric values of the restored site and the near-natural reference, the greater the restoration success.

\section{Comparing Entire Study Areas or Subset Clips}

A methodological problem that occurs in many landscape studies is the comparison of study objects of different sizes (Frohn 1998; Saura and Martinez-Millan 2001). Because we know that the size of a study region influences some landscape metrics, we propose a new method (the stencil technique) that yields samples with constant sizes and shapes. This is an important prerequisite for comparing different areas to reduce bias due to different window sizes. Because the clips are artificial subsets of the natural patterns, data interpretation requires commentary. The stencil might truncate larger patches. The fragments of patches that are 
EMME

Mean

shape

index

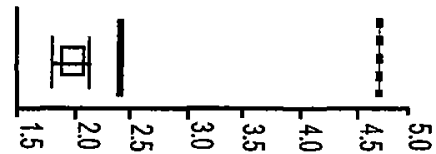

MOESA site II

MOESA site I
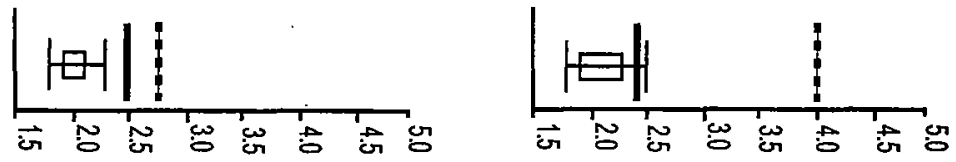

Median

patch

size
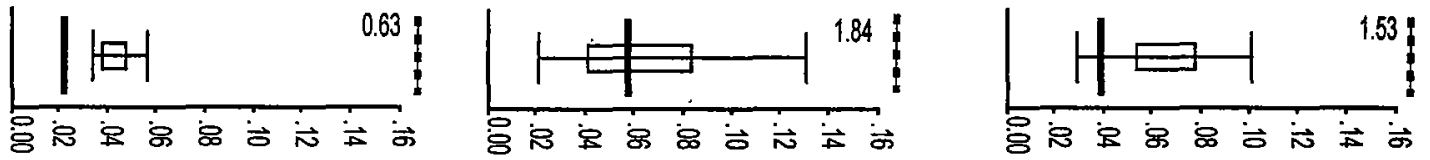

Mean

nearest

neighbor
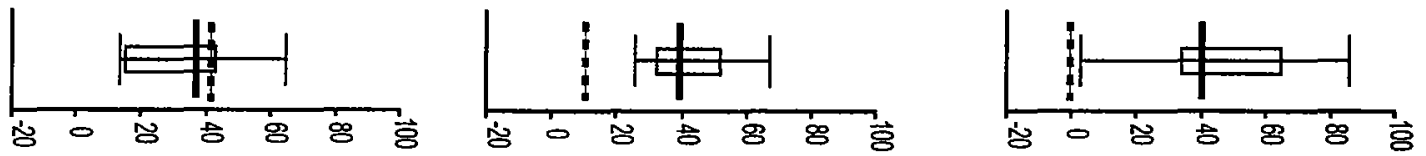

Mean

proximity

index
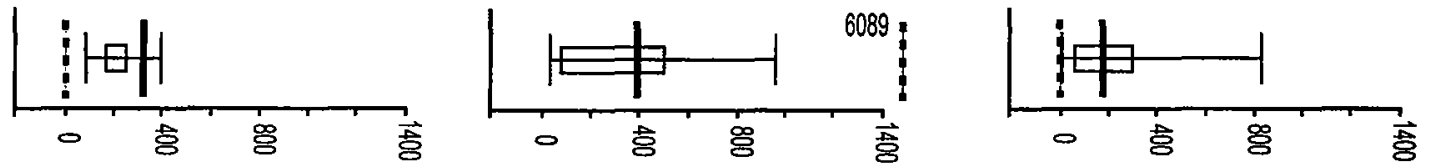

Interspersion

\& Juxtaposition

index
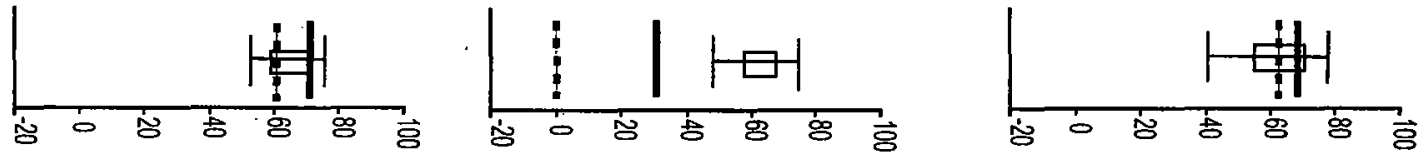

Edge density
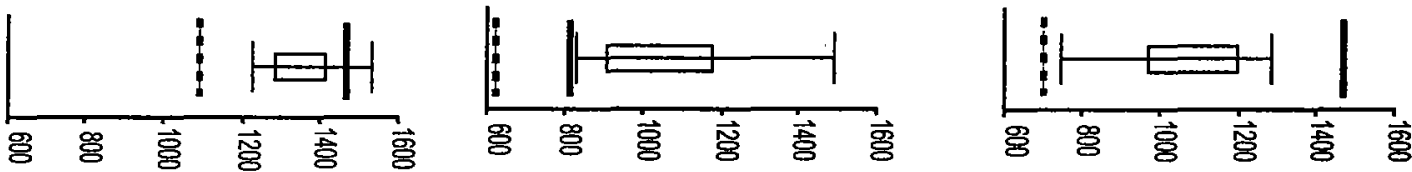

Patch

richness

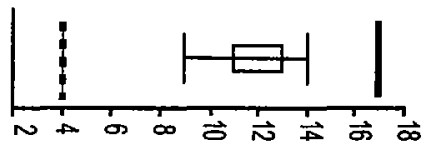

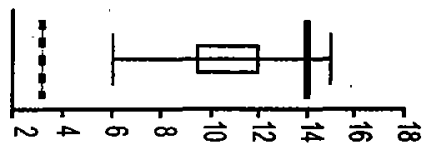

Figure 5. Landscape metric values calculated for the restored sites (black bar) compared to the range of metric values in the near-natural data subsets (box plot) and the regulated reference (dashed bar).

cut by the stencil border can be smaller than the minimum patch size, defined in the mapping process. Therefore, we used median values instead of mean values for the interpretation of patch size, as the median is less sensitive to these artificial outliers than the mean. The data subsets allow the characterization of the natural range of variability of habitat properties (composition and configuration) found at near-natural 
sites. This insight into the natural range of variability (Figure 5) helps in assessing whether the structural patterns found at a restoration site are within the natural range of variability of natural systems or if they differ from natural conditions (Poiani and others 2000).

\section{A Method Based on Comparisons of Restored and Near-Natural Sites}

Near-natural stretches define the endpoint to aim for in a restoration process. Thus, reference sites are needed to assess the degree of naturalness achieved by a selected restoration project (Downs 2001; Innis and others 2000; Milner 1996). However, a major limitation of this study is that the assessment of the postrestoration stage is not based on comparisons with near-natural sites in situ, but on comparisons with sites that are very similar to the site under investigation (analogy conclusion). If the reference sites do not belong to the same system as the restoration sites, the most important differences between the areas need to be known and to be taken into account during the evaluation process. Thus, natural references are best interpreted as "generalized models."

\section{Restoration of Riparian Landscapes}

Widening rivers increase the diversity of riparian habitat types. Evaluations generally show that there is a good match between habitat types in the restored sites and in the corresponding near-natural references. However, the overall patch richness of the restored sites is generally lower than at the near-natural references, and the mainly young seral stages are promoted by river widenings (Table 4). It could be argued that this is due to the age of the river widenings, as succession needs some time to develop late seral stages like shrub and woodlands. Restoration at the Emme River, for example, was finished around 10 years ago but still lacks the postpioneer stages initialized by the restoration process. The riparian woodlands found at the Emme restoration site are remnants of the situation before the restoration measures took place. However, even when there has been enough time for establishment, it is still doubtful that all of the seral stages naturally present in a floodplain will occur in the river widenings due to their limited size. This is confirmed by the metric analysis at the habitat level, which revealed a median patch size in the near-natural sites up to six times larger than that found at the present restoration sites. The sum of the mean patch sizes of each habitat class (excluding water) for the near-natural site along the Sense River is 7.5 ha. This area is one and a half times larger than the total extent of the river widening at the corresponding river widening along the Emme ( $5 \mathrm{ha}$ ). Thus, the size of the widenings does not allow the establishment of the whole range of floodplain habitats. It should also be noted that many river widenings solely open the channel but do not allow the former floodplain to be flooded. Therefore, new habitats establish in the channel where the stream velocity and scour is high. This hampers the development of late seral stages, which often develop at sites with little disturbance.

River widening generally creates a more natural landscape pattern, as exhibited in Figure 5: In many cases, the metric values calculated for the widenings are well within the range of values calculated for the nearnatural conditions and differ considerably from the values calculated for the regulated conditions. However, some metric values still deviate from the nearnatural variability: mean shape index (Emme, Moesa site I), median patch size (Emme), and edge density (Moesa site I + II). This more complex landscape pattern of the widenings can be explained as arising from the small size of the river widenings and the human excavation and filling works during construction. These works created a non-natural mosaic of islands and channels, which still remain, as there have been no major floods since the construction was finished to establish a more natural pattern. Only along the Emme was there a brief peak discharge $\left(470 \mathrm{~m}^{3}\right.$ discharge a day, with a mean discharge of $84.4 \mathrm{~m}^{3}$, with a biennual flood discharge of $259 \mathrm{~m}^{3}$ ), which presumably had only a minor impact on the landscape pattern.

\section{Conclusions}

Our investigations have shown that using the landscape approach described here can produce quick assessments of the restoration success of river widenings. Taking into account the limitations of the approach as described earlier, we conclude the following:

1. Reference sites, both regulated and near-natural, are prerequisites for successful assessment. The proposed stencil technique allows the restoration success to be assessed in cases where the regulated and the restored sites are much smaller in size than the corresponding near-natural reference. It allows an efficient and rapid assessment of the degree of naturalness achieved, as it readily indicates the similarities and differences among regulated, restored, and near-natural sites. The stencil method proved to be suitable for assessing to what extent a natural habitat pattern has been achieved by the restoration measures, taking into consideration the 
limited size of the site. Thus, a manager can check whether the restoration project has obtained a near-natural state, even if the area of the project is small due to socioeconomic constraints. However, when planning restoration measures, the size of the project must be large enough to provide sufficient space to re-establish a more natural landscape pattern.

2. Our approach is not confined to assessing the success of restoration projects along braided rivers. It is also applicable to assessing restoration projects aimed at restoring riparian landscapes along anabranching or meandering rivers.

3. (Semi)terrestrial habitat types cover a large part of the floodplain. The riparian zone therefore needs to be specially considered when assessing the success of restoration projects aiming to restore riparian landscapes. Our approach complements existing in-stream indicators and, thus, maximizes the quality of present-day assessment schemes. It allows the ecological integrity of a certain site to be assessed, which is defined as the full range of elements and processes expected in a region's natural habitat (Karr and Dudley 1981).

4. Landscape metrics are valuable indicators for the evaluation of projects that seek to restore riparian landscapes (river widening, dam allocation, etc.), as landscape metrics are surrogates for landscape functions and offer valuable insights into the similarities and differences between the landscape patterns of restored sites and their corresponding regulated and near-natural references. The proposed core set of landscape metrics (MSI, medPS, MNN, MPI, IJI, ED, \%Area, PR, see Table 3 for abbreviations) suffice to capture the principal properties of a natural riparian landscape pattern. They are intuitive and easily interpretable, which makes them easy to communicate to a wide range of stakeholders. The Manhattan metric $\left(d_{i j}\right)$ allows a quick and clear rating of restoration measures, thus supporting the evaluation process and the communication of findings.

5. River widenings provide opportunities for reestablishing riparian landscapes. However, they mainly promote young seral (pioneer) stages and a more complex habitat mosaic than near-natural sites. This is due to the limited size of these widenings. Although it appears to be possible to reestablish some aspects of fluvial ecosystems, river widenings cannot replace (near-)natural ecosystems. However, the success of such restoration projects could be increased by increasing the length and width of the river widenings.

\section{Acknowledgments}

We thank P. Englmaier and F. Herzog for helpful feedback on an earlier draft and M. W. Doyle, A. R. G. Large, M. G. Turner, and two anonymous reviewers for their extended comments and suggestions, which greatly improved the manuscript. We are also grateful to C. Ginzler for advice in the process of converting aerial photographs to orthophotos. This study is part of the Rhone-Thur-Project funded by the Swiss Federal Research Institute WSL, the Swiss Federal Institute for Environmental Science and Technology (EAWAG), the Swiss Federal Office for Water and Geology (FOWG), and the Swiss Agency for the Environment, Forests and Landscape (SAEFL).

\section{Literature Cited}

Amoros, C. 2001. The concept of habitat diversity between and within ecosystems applied to river side-arm restoration. Environmental Management 28:805-817.

Blaschke, T., and J. Petch. 1999. Landscape structure and scale: comparative studies on some landscape indices in Germany and the UK. Pages 75-84. in M. Maudsley, and J. Marshall (eds.), Heterogeneity in landscape ecology: Pattern and scale. LALE UK, Bristol, UK

Browder, J. A., L. N. May, A. Rosenthal, J. G. Gosselink, and R. H. Baumann. 1989. Modeling future-trends in wetland loss and brown shrimp production in Louisiana using thematic mapper imagery. Remote Sensing of Environment 28:45-52.

Brunke, M. 2002. Floodplains of a regulated southern alpine river (Brenno, Switzerland): Ecological assessment and conservation options. Aquatic Conservation: Marine and Freshwater Ecosystems 12:583-599.

Bürgi, M., and E. W. B. Russell. 2001. Integrative methods to study landscape changes. Land Use Policy 18:9-16.

Downs, P. 2001. Geomorphological evaluation of river restoration schemes: Principles, method, monitoring, assessment, evaluation. Progress?. Pages 243-249 in H. J. Nijland, M. J. R. Cals (eds.), River restoration in Europe: practical approaches. Institute for Inland Water Management and Waste Water Treatment / RIZA, Lelystad, the Netherlands.

Elkie, P.C., R.S. Rempel, and A.P. Carr. 1999. Patch Analyst User's Manual. A Tool for Quantifying Landscape Structure. Ontarion Ministry of Natural Resources NWST Technical Manual TM-001. Thunder Bay, Ontario.

Forman, R. T. T., and M. Godron. 1986. Landscape ecology. John Wiley \& Sons, New York.

Freeman, R. E., E. H. Stanley, and M. G. Turner. 2003. Analysis and conservation implications of landscape change in the Wisconsin River floodplain, USA. Ecological Applications 13:416-431.

Frohn, R. 1998. Remote sensing for landscape ecology. New metric indicators for monitoring, modeling and assessment of ecosystems. Lewis Publishers, Boca Raton, Florida. 
Gallandat, J.-D., Gobat, J.-M., and Roulier, C. 1993. Kartierung der Auen von nationaler Bedeutung. Vol. 199, Schriftenreihe Umwelt, Bundesamt für Umwelt, Wald und Landschaft (BUWAL). Federal Printing Office, Bern.

Gergel, S. E., M. G. Turner, J. R. Miller, J. M. Melack, and E. H. Stanley. 2002. Landscape indicators of human impacts to riverine systems. Aquatic Science 64:118-128.

Gilvear, D., K. Heal, and A. Stephen. 2002. Hydrology and the ecological quality of Scottish river ecosystems. Science of the Total Environment 294:131-159.

Gustafson, E J. 1998. Quantifying landscape spatial pattern: what is the state of the art? Ecosystems 1:143-156.

Hamazaki, T. 1996. Effects of patch shape on the number of organisms. Landscape Ecology 11:299-306.

Henry, C., C. Amoros, and N. Roset. 2002. Restoration ecology of riverine wetlands: A 5-year post-operation survey on the Rhone River, France. Ecological Engeneering 18:543-554.

Hering, D., and H. Plachter. 1997. Riparian ground beetles (Coleoptera, Carabidae) preying on aquatic invertebrates: A feeding strategy in alpine floodplains. Oecologia 111:261-270.

Herzog, F., A. Lausch, E. Müller, H.-H. Thulke, U. Steinhard, and S. Lehmann. 2001. Landscape metrics for assessment of landscape destruction and rehabilitation. Environmental Management 27:91-107.

Honnay, O., K Piessens, W. Van Landuyt, M. Hermy, and H. Gulinck. 2003. Satellite based land use and landscape complexity indices as predictors for regional plant species diversity. Landscape and Urban Planning 63:241-250.

Hunsaker, C. T., R. V. O'Neill, B. L. Jackson, S. P. Timmins, D. A. Levine, and D. A. Norton. 1994. Sampling to characterize landscape pattern. Landscape Ecology 9:207-226.

Innis, S. A., R. J. Naiman, and S. R. Elliott. 2000. Indicators and assessment methods for measuring the ecological integrity of semi-aquatic terrestrial environments. Hydrobiologia 422/423:111-131.

Jones, E. B. D., G. S. Helfman, O. J. Harper, and P. V. Bolstad. 1999. Effects of riparian forest removal on fish assemblages in southern Appalachian streams. Conservation Biology $16: 1454-1465$.

Karr, J. R., and D. R. Dudley. 1981. Ecological perspectives on water quality goals. Environmental Management 5:55-68.

Kondolf, M. G., and E. R. Micheli. 1995. Evaluating stream restoration projects. Environmental Management 19:1-15.

Lamprecht, J. 1992. Biologische Forschung: Von der Planung bis zur Publikation. Vol. 73, Pareys Studientexte. Verlag Paul Parey, Berlin.

Lausch, A., and H.-H. Thulke. 2001. The analysis of spatiotemporal dynamics of landscape structures. Pages 113-136 in R. Krönert, U. Steinhard, and M. Volk (eds.), Landscape balance and landscape assessment. Springer-Verlag, Berlin.

Lausch, A., and F. Herzog. 2002. Applicability of landscape metrics for the monitoring of landscape change: Issues of scale, resolution and interpretability. Ecological Indicators 2:3-15.

Li, H., and J. F. Reynolds. 1994. A simulation experiment to quantify spatial heterogeneity in categorical maps. Ecology 75:2446-2455.
Malanson, G. P. 1995. Riparian landscapes. Cambridge University Press, Cambridge.

McGarigal, K., and Marks, B. 1995. FRAGSTATS: Spatial pattern analysis program for quantifying landscape structure, US Department of Agriculture, Forest Service, Pacific Northwest Research Station Gen. Tech. Rep. PNW-ETR-351.

Miller, J. N., R. P. Brooks, and M.J. Croonquist. 1997. Effects of landscape patterns on biotic communities. Landscape Ecology 3:137-153.

Milner, A. M. 1996. System recovery. Pages 67-76 in G. Petts, P. Calow (eds.), River restoration. Blackwell Science Ltd., Oxford.

Mladenoff, D. J., T. A. Sickley, R. G. Haight, and A. P. Wydeven. 1995. A regional landscape analysis and prediction of favorable gray wolf habitat in the Northern Great Lakes Region. Conservation Biology 9:279-294.

Naiman, R. J., H. Décamps, and M. Pollock. 1993. The role of riparian corridors in maintaining regional biodiversity. Ecological Applications 3:209-212.

Nilsson, C., and M. Svedmark. 2002. Basic principles and ecological consequences of changing water regimes: Riparian plant communities. Environmental Management 30:468-480.

Pedroli, B., G. de Blust, K. Van Looy, and S. Van Rooij. 2002. Setting targets in strategies for river restoration. Landscape Ecology 17(Suppl.1):5-18.

Petts G., and P. Calow (eds.). 1996. River restoration. Blackwell Science Ltd, Oxford.

Pickett, S. T. A., and M. L. Cadenasso. 1995. Landscape ecology: Spatial heterogeneity in ecological systems. Science 269:331-334.

Pinay, G., J. C. Clément, and R. J. Naiman. 2002. Basic principles and ecological consequences of changing water regimes on nitrogen cycling in fluvial systems. Environmental Management 30:481-491.

Poiani, K. A., B. D. Richter, M. G. Anderson, and H. E. Richter. 2000. Biodiversity conservation at multiple scales: functional sites, landscapes, and networks. BioSciense $50: 133-146$

Potvin, F., K. Lowell, M.-J. Fortin, and L. Bélanger. 2001. How to test habitat selection at the home range scale: A resampling random windows technique. Ecoscience 8:399-406.

Qi, Y., and J. Wu. 1996. Effects of changing spatial resolution on the results of landscape patterns analysis using spatial autocorrelation indices. Landscape Ecology 11:39-49.

Rempel, L.L., J. S. Richardson, and M. C. Healey. 1999. Flow refugia for benthic invertebrates during flooding of a large river. Journal of the Nonth American Benthological Society 18:3448.

Riitters, K. H., R. V. O'Neill, C. T. Hunsaker, D. H. Wickham, D. H. Yankee, S. P. Timmins, K. B. Jones, and B. L. Jackson. 1995. A factor analysis of landscape pattern and structure metrics. Landscape Ecology 10:23-29.

Ripple, W. J., D. H. Johnson, and C. E. Meslow. 1991. Oldgrowth and mature forests near spotted owl nests in western Oregon. Journal of Wildlife Management 55:316318

Saura, S., and J. Martinez-Millan. 2001. Sensitivity of landscape pattern metrics to map spatial extent. Pho- 
togrammetric Engineering $\mathcal{E}^{2}$ Remote Sensing 67:10271036.

Thomson, J., M. Taylor, K Fryirs, and G. Brierley. 2001. A geomorphological framework for river characterization and habitat assessment. Aquatic Conservation: Marine and Freshwater Ecosystems 11:373-389.

Turner, M. G., R. H. Gardner, and R. V. O'Neill. 2001. Landscape ecology in theory and practice. Pattern and process. Springer-Verlag, New York.
Turner, M. G., R. V. O'Neill, R. H. Gardner, and B. T. Milne. 1989. Effects of changing spatial scale on the analysis of landscape pattern. Landscape Ecology 3:153-162.

Weller, D. E., T. E. Jordan, and D. L. Correll. 1998. Heuristic models for material discharge from landscapes with riparian buffers. Ecological Applications 8:1156-1169.

Wintersberger, H. 1996. Spatial resource utilisation and species assemblages of larval and juvenile fish. Archiv für $H y$ drobiologie 115(Suppl.):29-44. 